\title{
EDUCAÇÃO FÍSICA ESCOLAR E ESPORTE: SIGNIFICAÇÕES DE ALUNOS E ATLETAS
}

\author{
Deyvid Tenner de Souza Rizzo \\ Universidade Federal da Grande Dourados, Dourados, Mato Grosso do Sul, Brasil \\ Ágata Cristina Marques Aranha \\ Universidade de Trás os Montes e Alto Douro, Vila Real, Portugal \\ Clara Maria Silvestre Monteiro de Freitas \\ Universidade de Pernambuco, Recife, Pernambuco, Brasil \\ Jocimar Daolio \\ Universidade Estadual de Campinas, Campinas, São Paulo, Brasil \\ Jefferson Campos Lopes \\ Universidade de Ribeirão Preto, Ribeirão Preto, São Paulo, Brasil
}

\begin{abstract}
Resumo
O objetivo do estudo foi analisar as significações que alunos de Educação Física e atletas de um centro esportivo têm sobre o esporte, com o intuito de verificar as diferenças e "possíveis" semelhanças de seus significados. A pesquisa possui uma abordagem de natureza qualitativa e os sujeitos do estudo foram alunos da educação física escolar e atletas de um centro esportivo com idades entre de 13 a 18 anos; para estes foi aplicado um questionário e suas respostas foram analisadas com auxílio do software IRAMUTEQ. Os resultados indicam que as aulas de Educação Física ainda se caracterizam como reprodutoras de características competitivas e do esporte de rendimento, apontando para a necessidade do tratamento didático-pedagógico inerente a prática esportiva.
\end{abstract}

Palavras-chave: Esporte. Educação Física Escolar. Prática Esportiva.

\section{Introdução}

O estudo sobre a presença do esporte de rendimento ${ }^{1}$ nas aulas de Educação Física (EF) na escola se justifica por ainda ser um tema polêmico e engendrar alguns (des)encontros no meio acadêmico. Essa discussão é motivada desde a década de 1980 numa perspectiva crítica, mas porque esse debate ainda persiste?

Na passagem do século XX para o século XXI, a temática que envolve o esporte da escola e o esporte de rendimento foi avaliado por vários pesquisadores como um tema polissêmico. (KUNZ, 2006), (GAYA, 2009), (VAZ, 2009) Taffarel (2000), (LOVISOLO; BORGES; MUNIZ, 2013), (STIGGER, 2005). Interessante destacar que mesmo com aproximações e distanciamentos em suas bases teóricas, tais pesquisadores evidenciaram a possibilidade/necessidade de uma emancipação entre o esporte e a escola.

Mahoney e Eccles (2006) destacam vários resultados positivos que as práticas esportivas podem trazer aos jovens e às crianças, tais como: o aumento da autoestima,

\footnotetext{
${ }^{1}$ Neste estudo remete a ideia de esporte de alta performance, de excelência, espetáculo e alto nível.
} 
motivação, melhoria dos resultados estudantis, possibilidades de afastamento do tabagismo, álcool e drogas. Interessante ressaltar que crianças participam destas atividades por motivações intrínsecas (prazer, divertimento).

O presente estudo parte do princípio de que o esporte é um fenômeno rico de significados e reflexo de um processo de construção histórica e cultural de um povo, e que o "esporte em si" não traz valores de nenhum tipo, mas as técnicas e métodos utilizados para sua vivência e experimentação são responsáveis pela influência positiva ou negativa da prática esportiva na vida das pessoas.

Para tanto, nosso objeto de estudo não é propriamente o esporte em si, mas a relação entre o esporte de rendimento e a Educação Física Escolar (EFE). Com isso, o objetivo do estudo foi analisar os significados que alunos da rede básica de ensino $\left(1^{\circ}, 2^{\circ}\right.$ e $3^{\circ}$ Ano do Ensino Médio da Rede Estadual de Ensino) e atletas de um Centro Esportivo de DouradosMS/Brasil têm sobre o esporte, com o intuito de verificar as diferenças e "possíveis" semelhanças de suas percepções. Destarte, quais valores subjacentes são transmitidos para alunos e atletas adolescentes por meio do esporte nos dias atuais? E, como esses sujeitos significam a prática esportiva?

As representações desses atores sociais afloradas através de manifestações simbólicas e comportamentos foram analisadas em conjunto com observações participantes com base teórica na cultura corporal do movimento e teorias críticas. As perspectivas funcionalistas e existencialistas apenas demonstram a complexidade acerca o fenômeno esportivo.

"No esporte de rendimento as ações são julgadas pelo seu resultado final [...], valorizada em função do código binário da vitória derrota. Os meios empregados no treinamento, o próprio treinamento, tudo é medido pelo resultado final" (BRACHT, 2001, p. 4). No entanto, Gaya (2000) repudia essa percepção de Bracht e de acordo com seus estudos esclarece que diferentemente do que muitos apregoam normalmente sobre crianças e jovens ligadas ao esporte de rendimento, como por exemplo, alunos participantes dos Jogos da Juventude e atletas jovens em várias modalidades esportivas, sugerem que seus níveis de aptidão física referenciadas à saúde apresentam níveis satisfatórios, enquanto a maioria dos estudantes que apenas praticam esportes na EFE encontram-se em condições precárias.

Daolio (1995, p. 135) retrata que é um fato a $E F$ ter excluído ${ }^{2}$ inúmeros alunos que não se enquadram nos modelos de habilidade pré-definidos, visando um esporte de alto nível, partindo do "pressuposto que a Educação Física Escolar deve ser para todos os alunos, sejam eles habilidosos e robustos, ou descoordenados, baixinhos, gordinhos, de óculos ou meninas".

A partir desses pressupostos, Stigger (2005) busca saber em que medida poder-se-ia pensar numa visão multicultural para a pratica esportiva, e/ou até quando iria a hegemonia do esporte de rendimento, na sua pretensa influência na construção de uma monocultura no contexto desta prática social. O esporte de rendimento é visto com enorme força no sentido da sua hegemonia cultural, pois ele é visto como passível de ser transformado, tanto no contexto do lazer, como no da escola.

As atividades esportivas precisam de caráter educacional, objetivando desenvolver os jovens alunos para favorecer a consciência de seu próprio corpo, explorando seus limites, aumentando suas potencialidades, desenvolvendo o espírito de solidariedade de cooperação mútua e de respeito pelo coletivo (SILVA; DOMINGOS, 2014).

Reflexão semelhante é encontrada na obra de Kunz (2006), quando debatida a possibilidade da "Transformação didático-pedagógica do esporte", fazendo uma "análise dos significados do esporte". E é sobre a proposta de transformação didática dos esportes que concentra a perspectiva por uma prática esportiva pautada na cultura de movimento.

\footnotetext{
${ }^{2}$ Pelo que percebemos continua excluindo.
} 
Como apontam Silva; e Domingos (2014), Machado et al., (2015), Barbosa e Araújo (2015), estudos sobre intervenções educacionais dadas ao esporte se mostram de extrema relevância para a sociedade, sobretudo quando pensamos nas novas gerações, responsáveis, em primeira instância, pelas mudanças sociais futuras e pela renovação dos valores e tradições. Se as tradições estão em constante reconstrução, valores novos surgem, nem sempre tão positivos ou altruístas como eticamente desejável. Impõe-se então a responsabilidade moral da sociedade em geral, com ênfase na família, escola e demais instituições encarregadas de educar formalmente os jovens, pelo processo de transmissão de valores positivos.

Considerando os movimentos críticos da EF a partir de 1980 que questionam as possibilidades educacionais do esporte, com essa breve apresentação percebemos que temos cerca de 36 anos de discursos de pesquisadores com abordagens diferentes que visam a reorganização estrutural e educacional do esporte dentro e fora contexto escolar. Contudo, consideramos que nos dias atuais o passado ainda está muito presente, ou seja, práticas esportivas hegemônicas e com princípios do esporte de excelência presentes nas aulas de EF. Apontando para a necessidade do tratamento didático-pedagógico inerente a prática esportiva.

\section{O Caminho Percorrido ${ }^{3}$}

No presente estudo, optou-se por uma abordagem de natureza quali-quantitativa, pois como Limena e Rodrigues (2006) afirmam, é a mais indicada para investigar problemas que somente os procedimentos estatísticos não podem alcançar ou representar, em virtude de sua complexidade. Entre esses problemas, destacam-se aspectos sociais, psicológicos, opiniões, comportamentos, atitudes de indivíduos ou de grupos. Por meio dessa abordagem, tenta-se descrever e analisar a complexidade das significações dos acadêmicos relacionadas ao esporte educacional.

Os sujeitos do presente estudo compreenderam 100 atletas (entre meninos e meninas) devidamente matriculados em alguma modalidade esportiva num Centro Esportivo em Dourados-MS (Futsal, Futebol e Karatê), e 100 alunos (entre meninos e meninas) que frequentam as aulas de Educação Física nos $1^{\circ}, 2^{\circ}$ e $3^{\circ}$ Ano do Ensino Médio em uma escola da Rede Estadual de Ensino no Estado de Mato Grosso do Sul; com idades que variaram de 13 a 18 anos.

Um questionário foi utilizado para analisar as significações dos alunos/atletas acerca do esporte, sua organização foi baseada na versão do questionário que MacDonald et al. (2012) propõe aos pesquisadores interessados em experiências de crianças e adolescentes que praticam algum esporte, o Youth Experience Survey for Sport (YES-S); aproximando uma tradução para língua portuguesa entendemos: Pesquisa de Experiência na Juventude pelo Esporte (PEJ-E).

Para a análise das respostas abertas dos atletas e alunos, o software Analyses Multidimensionnelles de Textes et de Questionnaires (IRAMUTEQ) foi utilizado para análises textuais do tipo: pesquisa de especificidades de grupos; análises de similitude e nuvem de palavras. Essas ferramentas ofereceram a oportunidade de analisar diferentes grupos de palavras que foram utilizadas pelos atletas e alunos no questionário, e com isso, categorizar as palavras em classes, e consequentemente, visualizar aproximações e distanciamentos em seus discursos.

\footnotetext{
${ }^{3}$ Este estudo é resultado de parte de uma tese de doutoramento em Ciências do Desporto na Universidade de Trás os Montes e Alto Douro, tendo sido aprovado pelo Comitê de Ética em Pesquisa da Universidade Federal da Grande Dourados-MS (CAAE: 50341915.4.0000.5160/ Número do parecer: 1.402.554).
} 
Parte dos dados obtidos nas questões objetivas dos questionários foi tratada na planilha eletrônica Excel, posteriormente calculadas as frequências e percentuais das respostas dos sujeitos a cada uma das questões fechadas.

\section{Resultados e Discussão}

As duas primeiras perguntas do questionário aplicado aos alunos e atletas dizem respeito a informações pessoais como idade e gênero, a terceira pergunta questiona: "Você acredita que todas as pessoas podem praticar esportes? Por quê?". Entre os 200 sujeitos participantes do estudo, apenas três (dois do centro esportivo e um da escola) acreditam que o esporte não é para todos e suas respostam caminham para mesma direção, afirmam que nem todos podem praticar esportes devido a possíveis problemas de saúde.

Na figura a seguir observamos a "nuvem de palavras", que é uma análise lexical mais simples, porém graficamente interessante e corresponde as respostas da terceira questão. Ela consegue nos mostrar que até mesmo o jogo de queimado/queimada ${ }^{4}$ foi utilizado pelos sujeitos para demonstrar que o esporte pode ser realizado por todos. Mas o eixo centralizador é a palavra "esporte", que se encontra ligada com mais intensidade ao futebol, basquetebol e handebol. "Autoestima, satisfação, superar, disciplina," conduzem discursos de alunos e atletas, que pretendem demonstrar que o esporte pode contribuir para a melhoria da qualidade de vida da pessoa, porém, palavras como "sacrificar, preguiçoso, sofrimento, tímido, nervoso, inquietação" estão com mais freqüência presentes nas falas dos alunos de EFE, o que pode indicar que estes sujeitos visualizam o esporte como um "desafio maior", ou seja, parece que existe uma relação de tensão permanente entre esporte e aluno.

Figura 1 - Nuvem de Palavras

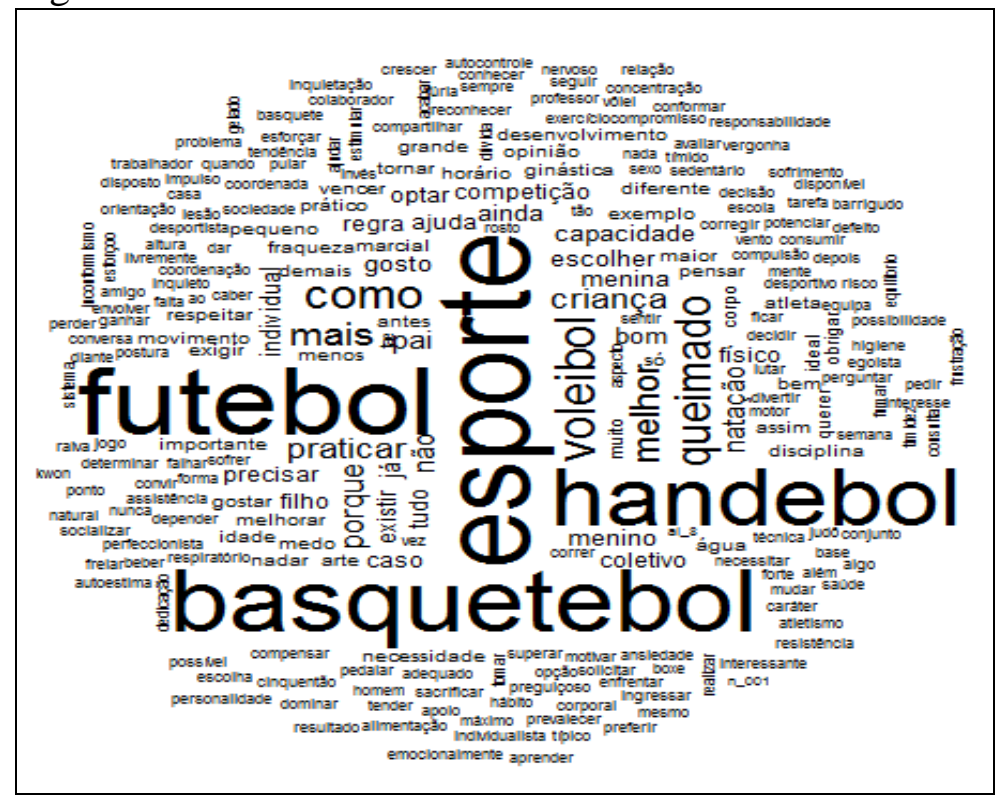

"Você aprendeu a respeitar os outros durante a prática esportiva?" Essa foi a quarta pergunta. Seus resultados são apresentados no gráfico a seguir (ver gráfico 1) juntamente com as respostas da quinta pergunta: "Você se sente estressado durante a prática esportiva?". Interessante observar que apenas 38\% dos alunos afirmaram que aprenderam a respeitar os outros durante a prática esportiva, enquanto no centro esportivo $86 \%$ dos atletas garantiram o

\footnotetext{
${ }^{4}$ Esse jogo é muito popular entre os alunos na escola, pois compõe um quadro competitivo entre outras modalidades num torneio regional que a escola participa.
} 
aprendizado desse valor. Isso pode sugerir que o esporte como conteúdo na EFE, especialmente para esses alunos, está carente de valores educacionais que demonstrem positividade nas ações de um sujeito para o outro. A quinta pergunta

Gráfico 1 - Respeito e Stress entre alunos e atletas

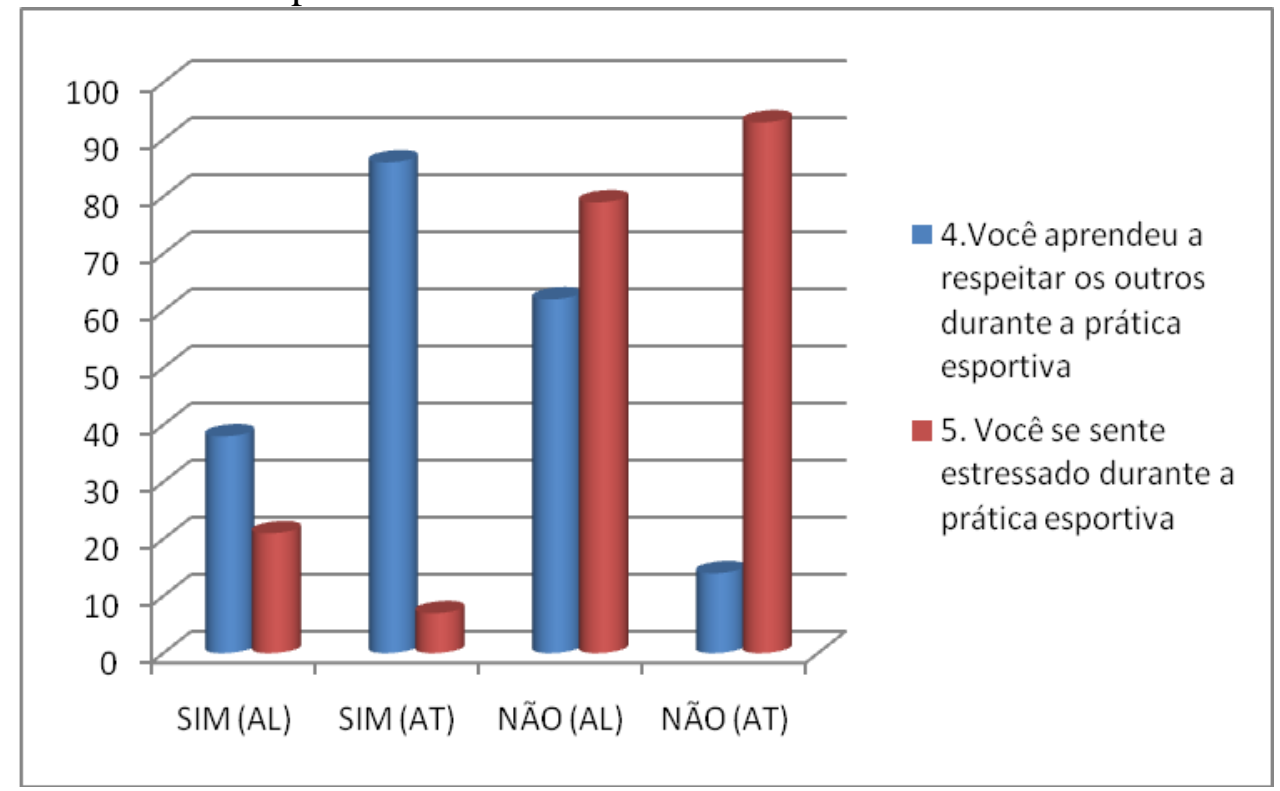

Ainda que a maioria de alunos e atletas apontaram não se sentirem estressados 5 durante a prática de esportes (79\%alunos e 93\%atletas), acredita-se que o professor na EFE deve dar atenção especial para os valores sociais que podem ser carregados com a prática esportiva. Freitas e Stigger (2016) buscam compreender o que leva uma criança a continuidade e participação na prática esportiva, e constatam que a experimentação dos limites e possiblidades dos movimentos, construção de vínculos de amizade e experiências para além da prática esportiva também são determinantes para permanência no esporte.

A análise sobre a prática esportiva educacional se mostra de grande relevância ao levarmos em consideração quando Rizzo et al. (2014) salientam que o esporte pautado em valores educacionais contribui de modo prático para as relações interpessoais, distancia da violência, das drogas; melhora a saúde física e mental; favorece o desenvolvimento da qualidade de vida; enfim, seja no âmbito cultural, biológico ou social, a lista dos benefícios é extensa. No entanto, a análise dos impactos diretos do esporte na vida de crianças e de jovens, pode colaborar efetivamente para a desmistificação de valores positivos e negativos que, por vezes, são atribuídos à prática esportiva.

\footnotetext{
${ }^{5}$ Aqui o termo de estresse possui como juízo a aflição e adversidade, comportando sensação de angústia e transtorno.
} 
A sexta questão foi objetiva de escala e questionou: "Quem te incentivou a praticar atividades esportivas?". Os alunos e atletas poderiam marcar uma opção das quatro oferecidas, a saber: pais, amigos, professor de EF ou outros (ver resultados no gráfico 2):

Gráfico 2 - Incentivo ao esporte

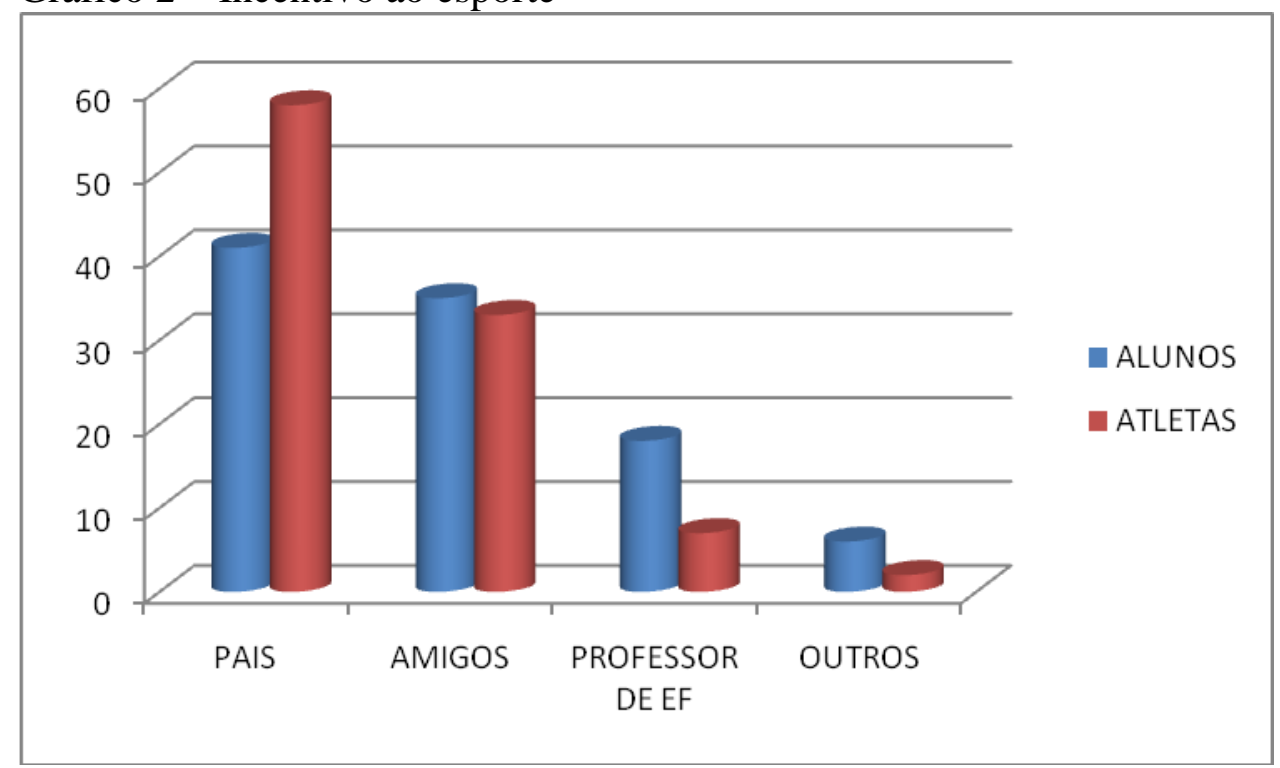

Percebe-se que é elevado o número de atletas incentivados pelos pais a praticar algum esporte (58\%) do que alunos no ambiente escolar (41\%). Já a influência de amigos é equilibrada entre ambos os grupos. Para tanto, chama a atenção o incentivo com origem do professor de EF, os alunos da escola tem maior influencia deste profissional para participar de alguma modalidade esportiva do que atletas no centro esportivo, talvez pelo segundo grupo ser influenciado pelo técnico/treinador.

Portanto, a figura do professor na EFE é de extrema importância para a manifestação do esporte na vida de crianças e adolescentes. Machado et.al (2015) declara que o esporte deve ter significado educacional altamente relacionado a socialização, destaca ainda que esses são os significados que permeiam os demais, uma vez que a busca de redes de relacionamento e de integração social estão presentes em qualquer significado que se dê à prática esportiva.

$\mathrm{Na}$ sétima questão os sujeitos foram orientados a assinalar o principal motivo que os levaram a praticar esportes (ver gráfico 3). Os resultados apontam a mínima influência da moda, televisão, o anseio por mais amigos ou indicação médica. 
Gráfico 3-Motivo para praticar esportes

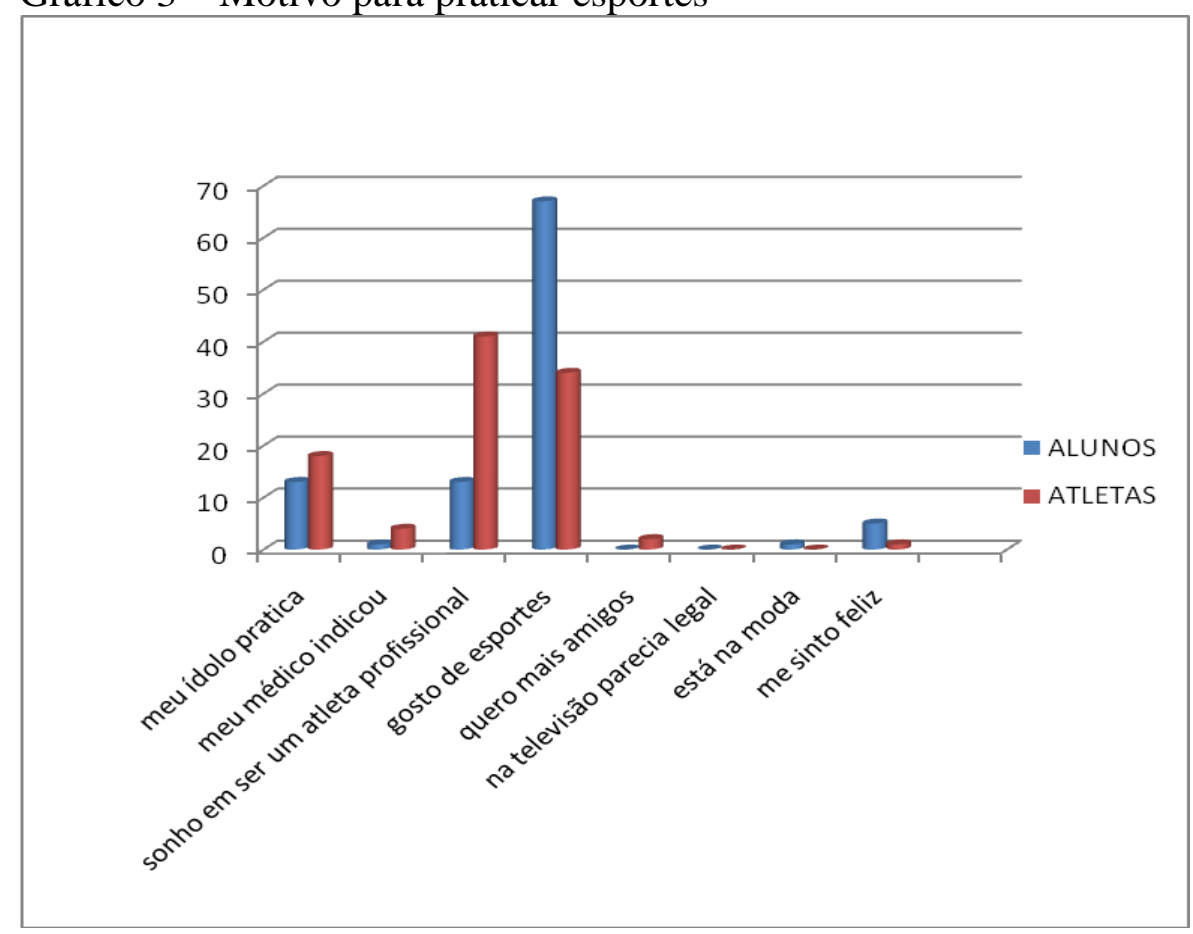

Contudo, observa-se uma grande divergência de opiniões entre os dois grupos (de atletas e alunos) quando a opção é referente ao sonho de ser um atleta profissional, apenas $13 \%$ dos alunos compartilham esse sonho, enquanto $41 \%$ dos atletas almejam atingir esse nível de profissionalismo atlético.

(STIGGER, 2001)Não é de se estranhar que o sonho em se tornar um atleta profissional esteja mais presente nos adolescentes do centro esportivo do que os alunos da EFE, pois estes evidenciam em seus discursos um contexto diferente relacionado ao esporte, que muitas vezes é envolvido por dificuldades, exclusão, etc., contanto, esses fatores não são exclusividade de um esporte de rendimento, mas sim, de uma prática excludente do professor de Educação Física. "Não gosto de nenhum esporte, pois sempre fico de fora", esse foi o comentário de uma aluna na escola (um dos que apontaram que o esporte não é para todos) que demonstra como é frágil a relação aluno e esporte em determinadas situações e espaços, nesse caso a EFE.

Leituras de Barbieri (2001) possibilitam entender que o esporte educacional embasase em princípios similares aos defendidos pela visão emancipadora. E estranhamente o 
esporte escolar, contrariamente, tem reforçado valores próprios, como uma prática esportiva com competição exacerbada, individualista e excludente.

$\mathrm{Na}$ oitava questão os sujeitos foram interrogados sobre: "Qual o esporte que você mais gosta de praticar? Por quê?" (ver figura 2). Podemos perceber que pela maior ocorrência de palavras, a que mais se destaca tanto para alunos quanto para atletas é o futebol.

Figura 2 - Nuvem de Palavras sobre o esporte mais praticado

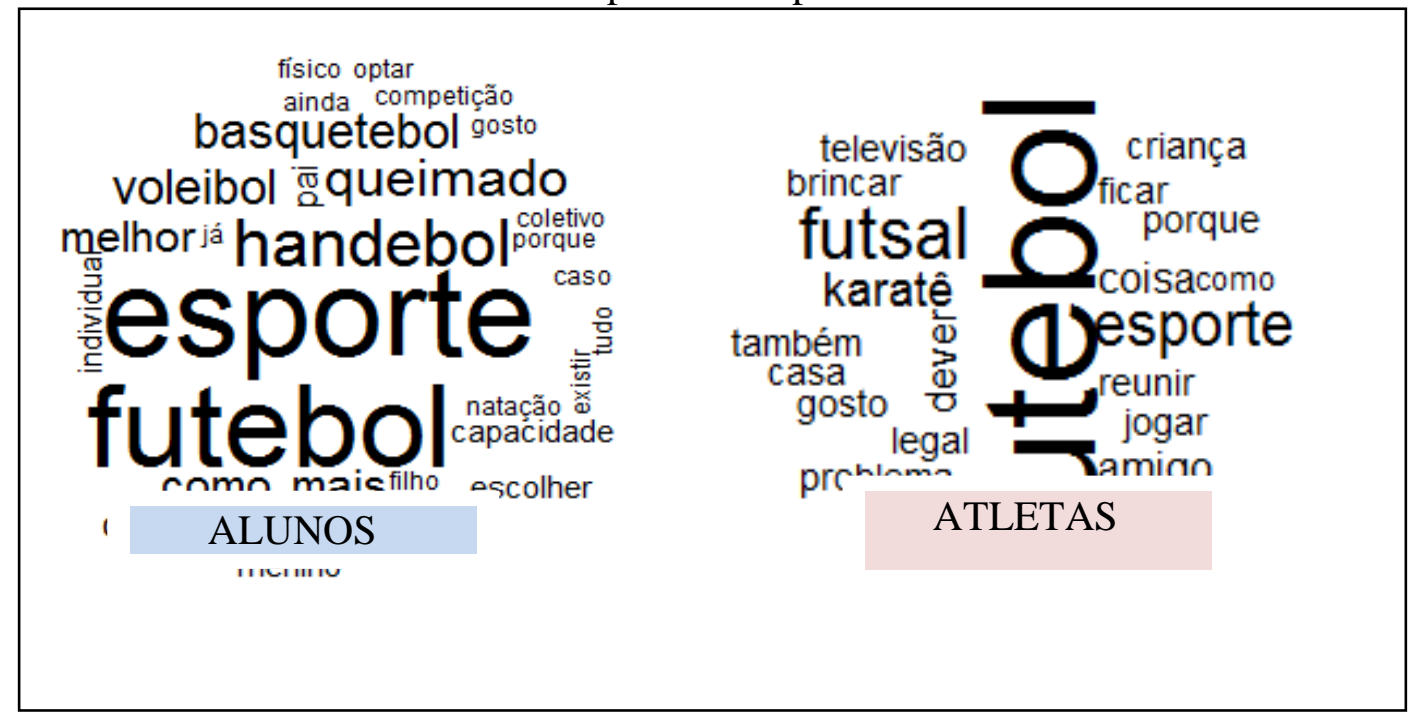

No grupo dos alunos também apareceram com frequência o handebol, queimada, voleibol e natação, já entre os atletas o futsal, e com menor presença o Karatê. Mas a resposta que mais chamou a atenção foi a de um aluno de 17 anos da escola que disse: "Prefiro o futebol porque é a melhor maneira de ser incluído, pois sou surdo". Notório perceber que a pouco uma aluna dizia ser excluída pelo esporte e agora este aluno parece ser incluído devido sua participação numa prática esportiva. Esse contexto direciona-se a favor com o que Stigger e Lovisolo (2009) apregoam em relação à prática esportiva no contexto escolar, ou seja, o esporte é o que fazemos com ele e não o que ele é. Nesse sentido Machado et al. (2015) aponta que os diferentes elementos constitutivos das modalidades esportivas - fundamentos, princípios, características, regras, estratégia e tática do jogo, entre outros - devem ser, aos poucos, apresentados de maneira simples e em nível de exigência adequado às habilidades e capacidades físicas, motoras, cognitivas, emocionais e sociais de uma criança que está iniciando um novo processo.

"Desta maneira o esporte passaria a desempenhar uma ou várias funções na sociedade e seria um elemento de reprodução desta realidade" (STIGGER, 2002, p. 24). Não importa se o adolescente vai jogar futebol ou jogar bola, desde que entenda que o ato de chutar, correr, driblar, gingar com o corpo são ações que poderão ser necessárias para algum momento de sua vida. 
Neste caso, a intenção pedagógica do professor em direção a quaisquer tipos de modalidade esportiva definirá o nível de aceitação ou não entre os alunos, pois cabe a EFE transformar e estimular a compreensão sobre os esportes, conduzindo o sujeito a refletir sobre o movimento historicamente produzido pelo ser humano.

No quadro a seguir (ver quadro 1$)^{6}$ são apresentadas algumas das significações dos sujeitos do estudo referente à questão número nove: "Qual o esporte que você menos gosta de praticar? Por quê?"

Quadro 1 - Significações do Esporte Educacional

\begin{tabular}{|l|l|}
\hline ALUNOS & ATLETAS \\
\hline Futebol: nunca me passam a bola & Handebol: é muito agressivo \\
\hline Voleibol: não sou bom & Basquete: Sou pequeno \\
\hline Basquete: porque é chato & Handebol: sempre me machuco \\
\hline Voleibol: acho que é mais para mulheres & Basquete: tem muitos pontos \\
\hline Voleibol: é muito chato & Basquete: sou muito baixo \\
\hline Voleibol: porque ninguém gosta & Voleibol: é muito parado \\
\hline Queimada: as boladas machucam & Tênis de mesa: sou muito lenta \\
\hline Voleibol: Atrapalha na quadra & Natação: tenho medo d'água \\
\hline Futebol: Os meninos que jogam & Handebol: é violento \\
\hline Não gosto de nenhum esporte & Não tem: gosto de todos \\
\hline
\end{tabular}

Nas falas dos atletas, a modalidade handebol aparece com muita frequência como um esporte violento e que ocasiona dores, possivelmente estes sujeitos tiveram algumas experiências negativas com o treinamento desse esporte especificamente. Neste grupo identificou quatro categorias, a primeira relacionada a aspectos físicos (baixa estatura, movimentos lentos); a segunda ligada ao medo (medo de se machucar ou do ambiente que se realiza o esporte); a terceira que gosta de praticar "todos" os esportes e a quarta corresponde a alguma discordância em relação a aspectos técnicos e táticos do jogo.

Entretanto, centremos a observação nos depoimentos dos alunos da EFE. Neste grupo foram identificadas cinco categoria, a primeira diz respeito a questões de habilidades específicas (alunos que acreditam ser "ruins"" no esporte); a segunda está relacionada ao medo (de se machucar durante um jogo); a terceira direciona-se aos rótulos (futebol é para meninos e voleibol para meninas).

A quinta categoria apareceu com muita intensidade no grupo de alunos da EFE e está ligada a desmotivação relacionada ao esporte ("é chato fazer..." dizem os sujeitos). Neste direcionamento Lovisolo et al. (2013) argumentam que se a prática atrelada ao esporte for chata, se não emocionar, se não for uma atividade antitédio e se não se situar no horizonte dos sonhos dos praticantes, terá pouquíssimos alunos em qualquer sistema que valorize a liberdade de escolha das atividades escolares. Se a atividade proposta é um tédio e se não se cruza com os sonhos, logo, apenas a repressão fará com que os estudantes participem. Se a participação é determinada pela obrigação normativa podemos obter como resposta a presença ausente, participação muito pequena, com "p" minúsculo. Por isso, como aponta Barbosa e Araújo (2015), ao reconhecermos o esporte como uma produção cultural, compreendemos

\footnotetext{
${ }^{6}$ Para este quadro foram selecionadas algumas respostas dos 200 depoentes para ilustrar as diferenças entre as categorias identificadas.

${ }^{7}$ Neste caso, o sujeito acredita que não possui características necessárias para participar de certa modalidade esportiva.
} 
que o mesmo expressa atitudes humanas, que podem representar inclusão ou exclusão, transformações ou reproduções.

Do mesmo modo que a emoção deve persistir durante toda a prática esportiva, a tarefa do professor de EF é mediar esse sentimento, direcioná-lo de maneira equilibrada para que este gere um comportamento motivador entre seus alunos, e, que a recompensa se manifeste com a satisfação pessoal em participar e se sentir um sujeito ativo no ambiente esportivo.

"Você tem alguma outra atividade esportiva fora da escola/centro esportivo? Fale sobre isso?", essa foi a décima questão cujos resultados são apresentados a seguir (ver figura 3). Pode-se constatar que $56 \%$ dos alunos praticam esportes fora da escola e $83 \%$ dos atletas também praticam algum outro tipo de modalidade esportiva fora do centro esportivo. Essa questão foi aberta e foram identificadas duas categorias e uma subcategoria no grupo dos alunos.

Figura 3 - Dendograma

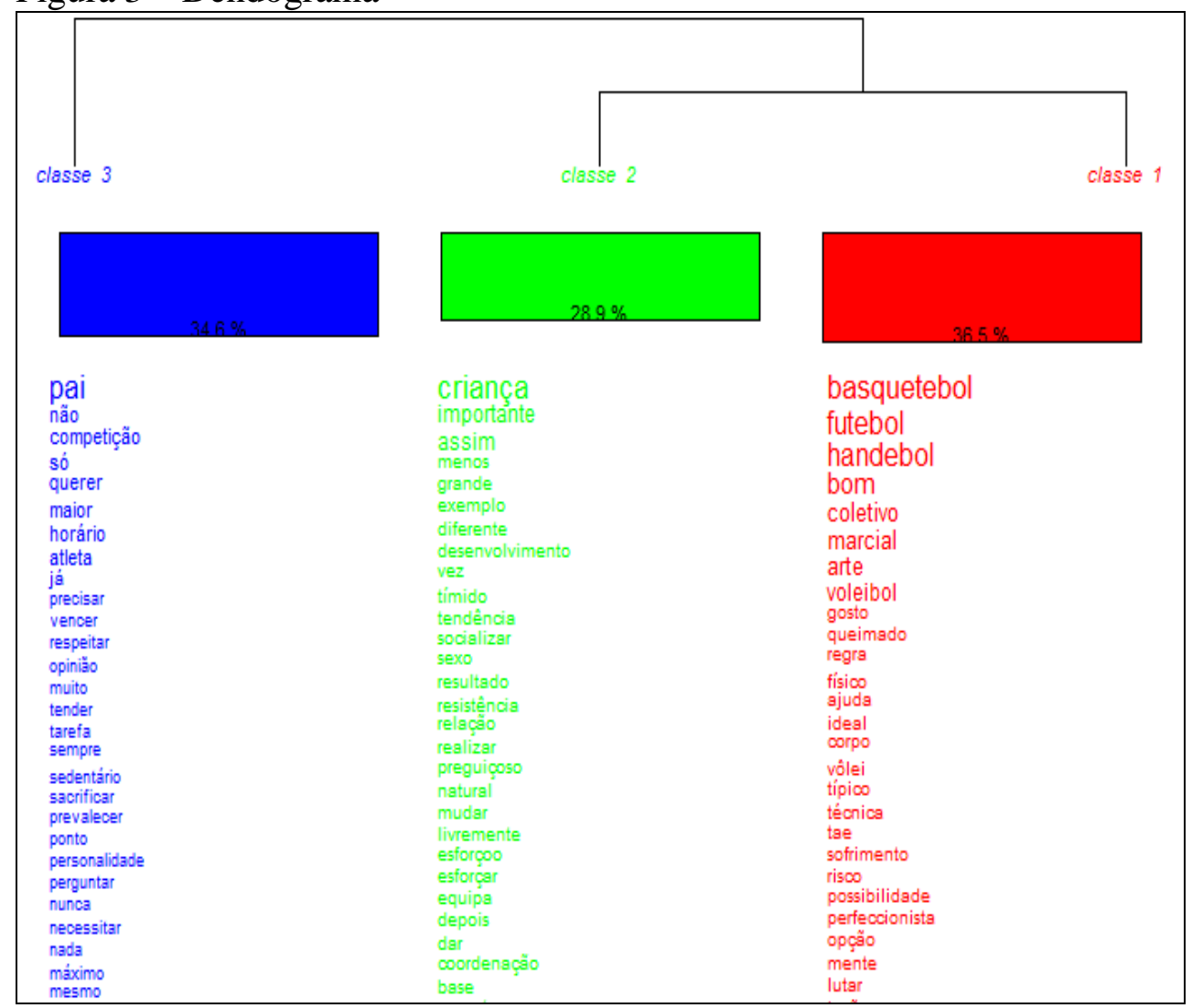

A primeira categoria (classe 3) possibilita entender que alunos que não praticam outras atividades físicas ainda dependem do transporte do pai ou os horários estão preenchidos com outras atividades no cotidiano. Já a segunda categoria é constituída de alunos que praticam mais de uma modalidade esportiva, e que se divide em duas subcategorias (classes 1 e 2), a primeira destaca algumas subjetividades, ou seja, que são muito ativos desde crianças e que o esforço sempre superou a preguiça e a segunda subcategoria enfatiza as principais modalidades que praticam como outra opção.

O desempenho educativo do esporte é inegável, independe do ambiente ou dos sujeitos envolvidos, se o professor de EF desenvolver um trabalho que mostre para o aluno (desde 
criança) a relevância e a importância das práticas esportivas na vida das pessoas, consequentemente o adolescente e posteriormente o adulto serão múltiplos disseminadores desse cenário esportivo para todos.

O esporte educacional busca o desenvolvimento integral dos alunos, preparando-os não somente para um esporte, mas para a vida. É nesse processo que o tratamento pedagógico que o professor reza na prática esportiva aparece com valor significante para a sistematização do esporte educacional.

Na questão número onze os sujeitos responderam a seguinte pergunta: "Você participa de competições ou festivais? Por quê?". E por meio da "análise de similitude" (ver figura 4), é possível que sejam escolhidos alguns parâmetros para a construção da árvore de coocorrências, possibilitando identificar as coocorrências entre as palavras e seu resultado que traz indicações da conexidade entre suas significações, auxiliando na identificação da estrutura da representação. Com isso, percebemos na imagem a seguir que a palavra esporte foi norteadora das respostas dos atletas, tendo ligações diretas com o futebol, o basquetebol, o handebol e por último o voleibol, enfim, as palavras "gosto" e "pratico" estão muito próximas ao eixo de similitude das palavras, demonstrando porque $94 \%$ dos atletas declaram que "sim", participam de festivais ou competições e gostam dessa prática.

Figura 4 - Análise de similitude

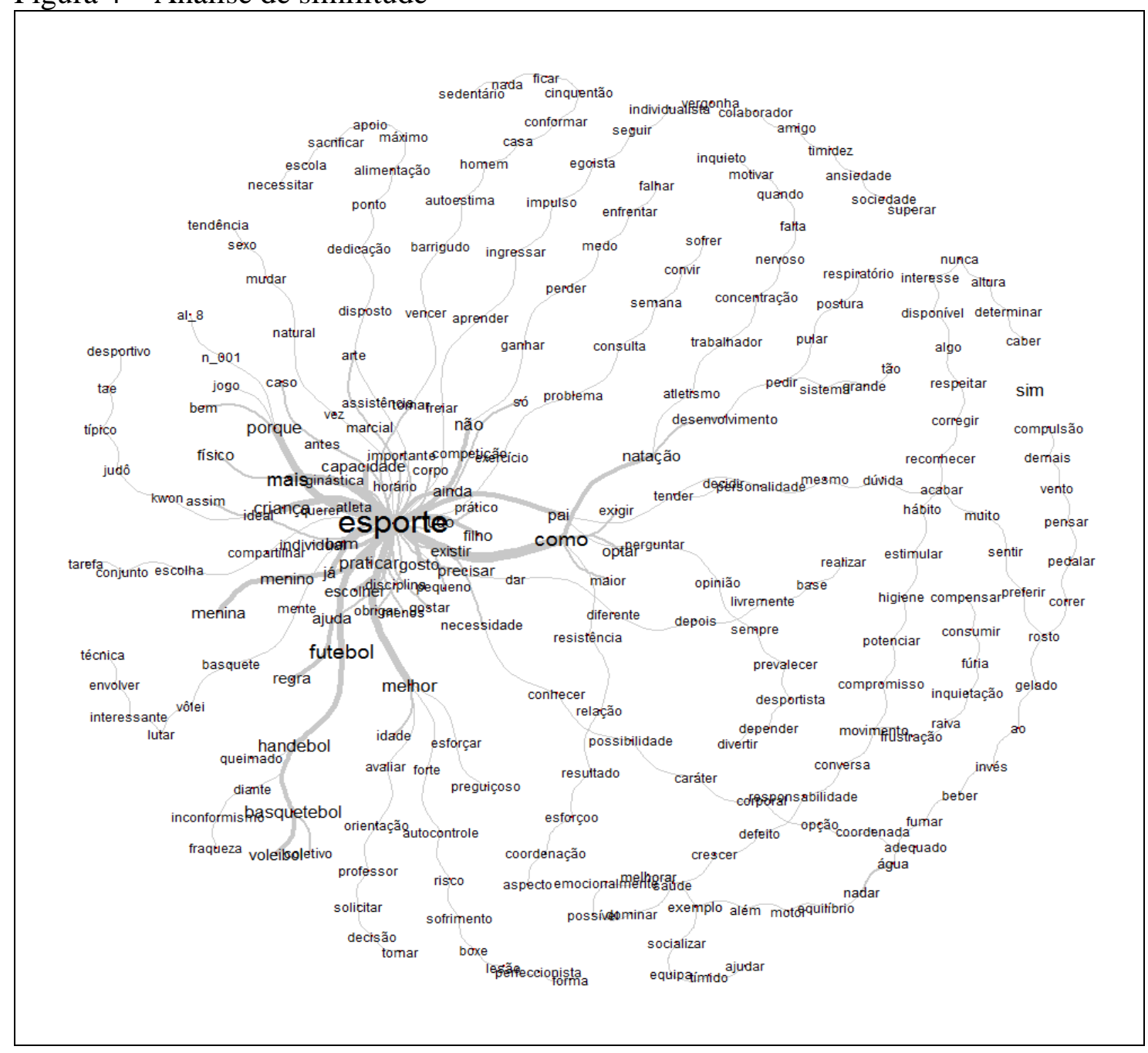

Contudo, os resultados bem diferentes dos alunos de EFE, onde $43 \%$ apenas afirmam que gostam de participar de festivais e competições, e os depoimentos para justificar esse 
"desgosto" foram bastante repetitivos, girando em torno basicamente da falta de habilidade e falta de oportunidade.

$\mathrm{Na}$ décima segunda pergunta os sujeitos foram interrogados sobre: "Cite um motivo que faz você continuar praticando esportes". Na décima terceira: "Escreva um motivo que te faria parar de praticar esportes". Ou seja, de maneira simplificada deveriam descrever apenas um motivo que faria com que abandonassem o esporte e outro que os motiva a continuar praticando esportes. No quadro a seguir (ver quadro 2) foram selecionadas algumas repostas para ilustrar algumas diferenças entre as significações dos alunos e atletas.

Quadro 2 - Abandono e permanência no esporte.

\begin{tabular}{|l|l|l|l|}
\hline ALUNOS & Parar & ATLETAS \\
\hline Continuar & $\begin{array}{l}\text { Quebrar parte do } \\
\text { corpo }\end{array}$ & $\begin{array}{l}\text { Ficar longe do } \\
\text { crime }\end{array}$ & $\begin{array}{l}\text { Falta de incentivo } \\
\text { da família }\end{array}$ \\
\hline Realizar sonhos & O desprezo & Melhorar saúde & Doenças \\
\hline $\begin{array}{l}\text { A diversão } \\
\text { ídolo }\end{array}$ & As tarefas da escola & Ser famoso & Me machucar \\
\hline O amor & Tédio & Defesas com chutes & Não andar mais \\
\hline A felicidade & Problemas de saúde & $\begin{array}{l}\text { Melhorar forma } \\
\text { física }\end{array}$ & $\begin{array}{l}\text { Problemas } \\
\text { cardíacos }\end{array}$ \\
\hline Correr, pular & $\begin{array}{l}\text { Ficar sempre } \\
\text { sentado no banco }\end{array}$ & Ser profissional & Meus pais \\
\hline $\begin{array}{l}\text { Ajuda meu } \\
\text { crescimento }\end{array}$ & Velhice & Respeito & Lesões \\
\hline $\begin{array}{l}\text { Exercício para o } \\
\text { corpo }\end{array}$ & Brigas & $\begin{array}{l}\text { Futuro melhor para } \\
\text { a família }\end{array}$ & Um acidente \\
\hline Ficar "bom" & Falta de vontade & $\begin{array}{l}\text { Nunca desistir dos } \\
\text { meus sonhos }\end{array}$ & A escola \\
\hline
\end{tabular}

Constatou-se que as significações dos alunos são muito mais carregadas de subjetividades que a dos atletas, ou seja, frequentemente aparecem em suas falas palavras como amor, felicidade, tédio, desprezo, etc. Causando a impressão que o maior desafio dos professores de EF é utilizar valores positivos inerentes a prática docente objetivando proporcionar um ambiente mais inclusivo para o esporte. Por isso, Kunz (2006) prega por uma expansão do conceito de esporte, isso não significa a extinção do esporte de rendimento, mas uma transformação desse fenômeno.

Nas significações dos atletas "a escola" apareceu onze vezes como um fator que poderia motivar o afastamento das atividades esportivas. Numa tentativa de ler as entrelinhas dessas respostas, acredita-se que os atletas queriam dizer que o alto índice de tarefas escolares para além da sala de aula corrobora para o abandono dos treinos.

Aqui, percebe-se uma inversão de valores, a escola deve ser considerada um dos ambientes mais importantes na vida social de um ser humano, um espaço que o sujeito se constitui como pensante e questionador. É nesse sentido que o esporte educacional busca conservar os valores positivos como compreensão, cooperação, superação entre tantos outros para despertar o potencial em cada indivíduo. Essa ação, por exemplo, possibilitará que alunos da EFE se distanciem de sentimentos como ódio, egoísmo, falta de vontade e tédio e se tornem sujeitos do processo de significação do movimento através do esporte e não meros 
objetos de uma prática mecanizada. Assim como pode proporcionar ao atleta a fazer novas leituras de mundo, e entender que a escola não é um empecilho para sua provável ascensão na carreira profissional, mas sim, um símbolo que desperta seu talento interior de maneira crítica. São esses pressupostos que valorizam e justificam a presença do esporte pautado em valores educacionais tanto na EFE quanto no esporte de rendimento.

\section{Considerações Finais}

Quando nos reportamos a analisar as significações que alunos da EFE e atletas de um Centro Esportivo têm sobre o esporte, assumimos um risco de generalizar as vivências e situações por meio do discurso desses sujeitos, por isso, buscamos (re)marcar diferenças e enfatizar semelhanças que estes alunos e atletas produzem por meio da prática esportiva.

Acreditamos no inegável mérito e prestigio social que o fenômeno esportivo proporciona, e nesse sentido a imagem da prática esportiva é construída equivalente as necessidades de seus mediadores, e desta forma, se caracterizam como reprodutores de características competitivas, de seletividade, de lazer, etc., e, consequentemente a reprodução do esporte de rendimento também se manifesta nas diversas instâncias sociais, e nesse contexto, a escola "não fica de fora", pelo contrário, percebemos diversas semelhanças nas significações dos atletas do centro esportivo e alunos da EFE.

Encontramos valores como disciplina e respeito com o outro muito mais presentes entre os atletas no Centro Esportivo que, no ambiente escolar nos grupos pesquisados. Isso comprova que podemos articular comportamentos positivos que foram encontrados no esporte de rendimento para o contexto escolar, pois entendemos que "o esporte não é", ele continua sendo. Esta concepção pode ser resultado do ato pedagógico do professor de EF; para que o aluno interprete o esporte como fenômeno prazeroso e emocionante, o professor deve significar esse conteúdo de forma solidária e tolerante, para que o resultado final seja um aluno que promova uma educação pelo esporte e se reconheça nesse espaço.

Para que a aliança entre esporte e escola seja feliz, e não resulte num desquite, é necessário garantir a democratização do desporto em geral como uma prática social que tematiza a cultura corporal do movimento. Apregoamos a sistematização de uma prática esportiva com tratamento educacional, mas para isso, o esporte deve ser alvo de tratamento didático-pedagógico a fim de fomentar uma cultura esportiva que independente do local de sua realização, seja causa de efeitos positivos (amizade, respeito, determinação, coragem, inspiração, etc.), e consequentemente se constitua como um elemento de transformação social.

Por fim, o debate teórico sobre o esporte na sociedade, mais especificamente num centro esportivo e na EFE, nos permite dizer que os movimentos críticos da EF a partir de 1980 que questionam as possibilidades educacionais do esporte têm cerca de 36 anos de discursos de pesquisadores com abordagens diferentes que visam a reorganização estrutural e educacional do esporte dentro e fora do contexto escolar. Contudo, principalmente a partir do discurso de alunos que indicam a exclusão nas práticas esportivas pela falta de habilidades específicas, identificamos que nos dias atuais o passado ainda está muito presente, ou seja, práticas esportivas hegemônicas e com princípios do esporte de excelência presentes nas aulas de EF, o que aponta para a necessidade da revisão do tratamento didático-pedagógico das atividades esportivas, e, consequentemente um convite para repensar as formas de ensinar o esporte pautado em valores positivos por meio de uma prática educativa.

\section{SCHOOL PHYSICAL EDUCATION AND SPORT: SIGNIFICATIONS STUDENTS AND ATHLETES}

\section{Abstract}


The aim of the study was to analyze the meanings that students of physical education and athletes a sports center have on the sport, in order to verify the differences and " potential " similarities of their meanings. The research has a qualitative nature and approach the study subjects were students of school physical education and athletes a sports center aged from 13 to 18; for this was a questionnaire and their responses were analyzed with the aid of IRAMUTEQ software. The results indicate that Physical Education classes are still characterized as breeding of competitive features and performance sport, pointing to the need for didactic-pedagogic treatment inherent in sport.

Keywords: Sport. School Physical Education. Practice Sports.

\section{EDUCACIÓN FÍSICA Y EL DEPORTE: SIGNIFICACIONES ESTUDIANTES Y ATLETAS}

\section{Resumen}

El objetivo del estudio fue analizar los significados que los estudiantes de educación física y atletas de un centro deportivo tienen en el deporte, con el fin de verificar las diferencias y similitudes "potenciales" de sus significados. La investigación es de naturaleza cualitativa y acercarse a los sujetos del estudio eran estudiantes de la educación física escolar y los los atletas de un centro deportivo edad del 13 al 18 años; para esto fue un cuestionario y sus respuestas fueron analizados con la ayuda de software IRAMUTEQ. Los resultados indican que las clases de Educación Física todavía se caracterizan por ser de cría de las características de la competencia y el rendimiento deportivo, que apunta a la necesidad de un tratamiento didáctico-pedagógico inherente en el deporte .

Palabras clave: Deporte. Escuela de Educación Física. Práctica Deportiva.

\section{Referências}

BARBIERI, C. A. S. Esporte educacional: uma possibilidade de restauração do humano no homem. Canoas: ULBRA, 2001.

BARBOSA, J. S.; ARAÚJO, M. A. L. DE. EDUCAÇÃO (FÍSICA) E ESPORTE - NAS TEIAS DE UMA PESQUISA-AÇÃO EXTENSIONISTA EM UMA UNIVERSIDADE PÚBLICA BAIANA. Movimento (ESEF/UFRGS), v. 21, n. 2, p. 391-403, 5 fev. 2015.

BRACHT, V. Sociologia critica do esporte: uma introdução. [s.l.] Centro de Educacao Fisica e Desportos da Ufes, 1997.

BRACHT, V. Esporte na escola e esporte de rendimento. Movimento (ESEF/UFRGS), v. 6, n. 12, p. XIV-XXIV, 23 out. 2001.

FREITAS, M. V. DE; STIGGER, M. P. A Formação de Crianças para o Esporte de Alto Rendimento: sobre "manobras" e diferentes apropriações dos treinos. Pensar a Prática, v. 19, n. 1, 31 mar. 2016.

GAYA, A. Sobre o Esporte para Crianças e Jovens. Movimento (ESEF/UFRGS), v. 6, n. 13, p. I-XIV, 2000. 
GAYA, A. Sobre o esporte para crianças e jovens. In: STIGGER, M. P.; LOVISOLO, H. R. (Eds.). . Esporte de rendimento e esporte na escola. Campinas: Autores Associados, 2009.

KUNZ, E. KUNZ, Elenor. Transformação didático-pedagógica do esporte. 7.ed. Ijuí: Ed. Unijuí, 2006. 7. ed. Ijuí: Unijuí, 2006.

LIMENA, M. M. C.; RODRIGUES, M. L. Metodologias multidimensionais em ciências humanas. [s.1.] Liber Livro, 2006.

LOVISOLO, H. R.; BORGES, C. N. F.; MUNIZ, I. B. Competição e cooperação: na procura do equilíbrio. Revista Brasileira de Ciências do Esporte, v. 35, n. 1, p. 129-143, 2013.

MACDONALD, D. J. et al. Psychometric properties of the youth experience survey with young athletes. Psychology of Sport and Exercise, v. 13, n. 3, p. 332-340, maio 2012.

MACHADO, G. V.; GALATTI, L. R.; PAES, R. R. PEDAGOGIA DO ESPORTE E PROJETOS SOCIAIS: INTERLOCUÇÕES SOBRE A PRÁTICA PEDAGÓGICA. Movimento (ESEF/UFRGS), v. 21, n. 2, p. 405-418, 5 fev. 2015.

MAHONEY, H. A.; ECCLES, J. Organized Activity Participation, Positive Youth Development, and the Over-Scheduling Hypothesis. Social Policy Report, v. 20, n. 4, p. 330, 2006.

RIZZO, D. S.; FONSECA, A. M. L. F. M. DA; SOUZA, W. C. Desenvolvimento Positivo dos Jovens (DPJ) através do Esporte: perspectivas em países da lígua portuguesa. CONEXÕES: Revista da Faculdade de Educação Física da UNICAMP, v. 12, n. 3, p. 106-120, 17 nov. 2014.

SILVA, B. O.; DOMINGOS, P. V. Os projetos especiais do Programa Segundo Tempo (2013-2014): ampliando a inclusão social por meio do esporte educacional.Porto Alegre: Centro de Memória do Esporte da Escola de Educação Física da Universidade Federal do Rio Grande do Sul, , 2014. . Acesso em: 22 jan. 2016

STIGGER, M. P. Esporte, lazer e estilos de vida: um estudo etnográfico. [s.l.] Editora Autores Associados, 2002.

STIGGER, M. P. Educacao Fisica, Esporte E Diversidade. [s.1.] Autores Associados, 2005.

STIGGER, M. P.; LOVISOLO, H. Esporte de rendimento e esporte na escola. [s.1.] Autores Associados, 2009.

TAFFAREL, C. N. Z. Desporto Educacional: realidade e possibilidades das políticas governamentais e das práticas pedagógicas nas escolas públicas. Movimento (ESEF/UFRGS), v. 6, n. 13, p. XV-XXXV, 2000.

VAZ, A. F. Técnica, esporte, rendimento. In: STIGGER, M. P.; LOVISOLO, H. R. (Eds.). . Esporte de rendimento e esporte na escola. Campinas: Autores Associados, 2009. 
Aprovado em: 16/05/2016

Endereço para correspondência:

deyvidrizzo1@gmail.com

Deyvid Tenner de Souza Rizzo

Universidade Federal da Grande Dourados

Rua João Rosa Góes, 1761

Vila Progresso

79825-070 - Dourados, MS - Brasil 